\title{
RINOPLASTIA DO NARIZ NEGRÓIDE POR VIA INTRA-ORAL SEM RESSECÇÕES EXTERNAS. AVALIAÇÃO DA EFICÁCIA DA TÉCNICA ${ }^{1}$
}

\author{
Helton Traber de Castilho \\ Bernardo Hochman ${ }^{3}$ \\ Lydia Masako Ferreira ${ }^{4}$
}

\begin{abstract}
Castilho HT, Hochman B, Ferreira LM. Rinoplastia do nariz negróide por via intra-oral sem ressecções externas: avaliação da eficácia da técnica. Acta Cir Bras [serial online] 2002 Set-Out;17(5). Disponível em URL: http://www.scielo.br/acb.
\end{abstract}

RESUMO - Objetivo: Avaliar a eficácia da técnica de redução da largura da base nasal do nariz negróide, modificando a inclinação dos eixos das narinas pela mobilização de tecidos internos, por abordagem intra-oral, evitando cicatrizes externas. Métodos: Foram operadas 11 pacientes adulta do sexo feminino, com idade variando entre 19 a 45 anos, distribuindo-se em 2 da raça caucasóide e 9 da raça negróide, sendo desta 5 de cor parda e 4 de cor negra. O método de fotografia foi padronizado, e as imagens em papel foram digitalizadas. Por meio de software foram mensurados nas fotografias pré-operatórias e com 3 meses após a rinoplastia, 8 índices relativos à base nasal baseados em pontos antropométricos. Os valores obtidos foram submetidos à análise estatística descritiva e inferencial. Resultados: Não houve diferença estatisticamente significante em 7 índices relativos a redução da largura da base nasal e à inclinação dos eixos das narinas. Apenas houve alteração significante no aumento do Ângulo Nasolabial $(\mathrm{p}=0,001)$. Conclusão: A técnica de rinoplastia de nariz negróide por via intra-oral sem ressecções externas, apenas com mobilização dos tecidos internos, não é eficaz para a reduzir a largura da base nasal.

DESCRITORES - Nariz. Rinoplastia. Raça negra. Antropometria. Fotografia. Fotogrametria.

\section{INTRODUÇÃO}

A maior parte da literatura em rinoplastia aborda operações estéticas em indivíduos caucasóides, e nas duas últimas décadas a rinoplastia tornou-se uma das operações estéticas mais freqüentes em pessoas de raça negra $^{(1,2)}$.

Existe um certo receio entre os cirurgiões de realizar incisões externas em procedimentos estéticos em negros devido ao maior risco de complicações como cicatrizes hipertróficas ou queloideanas, alterações de pigmentação cutânea e estenose da válvula nasal externa $^{(3)}$.

Os princípios básicos que regem a rinoplastia de nariz negróide são a redução das narinas, o estreitamento da base nasal e o aumento do dorso no perfil ${ }^{(4)}$.

A variedade de técnicas e táticas descritas na literatura a respeito da operação de nariz negróide atesta que apesar dos autores entenderem o problema, ainda não chegaram a um consenso.

Agrava o fato do nariz negróide apresentar-se com múltiplas variações anatômicas devido à miscigenação

1. Trabalho realizado no Setor de Rinologia da Disciplina de Cirurgia Plástica do Departamento de Cirurgia da Universidade Federal de São Paulo - Escola Paulista de Medicina (UNIFESP / EPM).

2. Professor Adjunto e Chefe do Setor de Rinologia da Disciplina de Cirurgia Plástica do Departamento de Cirurgia da UNIFESP / EPM.

3. Pós-Graduando do Curso de Pós-Graduação em Cirurgia Plástica da UNIFESP/EPM.

4. Professora Livre Docente, Titular e Chefe da Disciplina de Cirurgia Plástica do Departamento de Cirurgia da UNIFESP / EPM. 
racial. As várias matizes de narizes denominados genericamente de negróide são resultantes da mistura entre indivíduos negros com brancos e índios, e estes entre si ao longo do tempo ${ }^{(3)}$.

As incisões externas com ressecção de asa nasal ou assoalho das narinas ainda são mais utilizadas para reduzir a largura da base nasal ${ }^{(4,5)}$, apesar da cicatriz ou assimetrias poderem representar um estigma.

Leonardo da Vinci( ${ }^{(6)}$ já havia estabelecido que para narizes caucasóides a largura da base nasal deveria corresponder, no máximo, à distância entre as comissuras mediais das pálpebras.

KAMER e PARKES (1975) ${ }^{(3)}$ descreveram técnica conservadora para estreitar a base nasal por meio de sutura em U posterior à parte móvel do septo nasal, sem a necessidade de ressecar pele, cartilagem septal, ou de realizar osteotomias, descolamento cutâneo ou periostal,.

BERNSTEIN (1975) ${ }^{(4)}$ propôs técnica na qual não retira tecido da asa nasal, mas consegue um estreitamento às custas de transposição de retalhos cutâneos (zeta-plastia). Em casos de base nasal mais acentuada propôs um fechamento em V-Y a partir do sulco nasolabial.

WARD (1979) ${ }^{(7)}$ fez estudo direcionado à base nasal procurando estandardizar sua mensuração, assim como definir o formato ou inclinação das narinas para avaliar resultados.

SANTANA (1991) ${ }^{(6)}$ descreveu técnica pessoal para tratar nariz negróide sem ressecar asa nasal, diminuindo a largura da base mediante sutura em $U$ por abordagem intra-oral e descolamento periosteal.

WATANABE $(1994)^{(8)}$ descreveu técnica sem incisão externa para reduzir a base em nariz oriental, utilizando uma X-plastia na mucosa ao nível do ponto mais superior da curva do ramo lateral da cartilagem alar maior.

Mesmo quando a operação do nariz negróide é bem indicada e sucedida, o resultado geralmente não preenche os critérios de estética convencionalmente estabelecidos. Por isso, tem-se procurado realizar abordagens operatórias mais conservadoras no intuito de minimizar possíveis complicações, principalmente o quelóide $^{(3)}$.

Existe uma necessidade crescente dos cirurgiões plásticos desenvolverem técnicas sem incisões externas para nariz negróide ${ }^{(3,6,8)}$, e é neste contexto que se optou por desenvolver este trabalho.

O objetivo é avaliar a eficácia da operação de nariz negróide onde não se resseca asa ou assoalho nasal, apenas mobilizando-se tecidos internos por abordagem intra-oral para reduzir a largura da base nasal, modificando a inclinação dos eixos das narinas.

\section{MÉTODOS}

\section{Amostragem}

Foram selecionados 11 pacientes adultos portadores de nariz negróide provenientes do ambulatório da Disciplina de Cirurgia Plástica do Departamento de Cirurgia da Universidade Federal de São Paulo (UNIFESP / Escola Paulista de Medicina).

Todos os pacientes eram do sexo feminino (a escolha do sexo foi casual), com idade variando de 19 a 45 anos, sendo 2 da raça caucasóide e 9 da raça negróide, sendo desta 5 de cor parda e 4 de cor negra.

O critério de seleção utilizado foi o relato espontâneo do paciente na anamnese de queixa restrita à largura da base nasal ou ao tamanho das narinas (sic). Os pacientes somente foram liberados para a operação após serem submetidos a uma avaliação clínica e laboratorial.

Os critérios de exclusão de pacientes foram a realização de rinoplastia ou outra operação nasal prévia, a presença de desvio de septo, assimetrias das narinas visualmente significativas ou distúrbios psicológicos relevantes.

\section{PROCEDIMENTOS}

\section{1 - Técnica operatória}

A operação foi realizada sob anestesia geral e em decúbito dorsal horizontal. Infiltrou-se o ápice e dorso nasal com lidocaina a $2 \%$, bupivacaina a $0,5 \%$ e adrenalina em concentração de 1/200.000.

Após tricotomia em ambos os vestíbulos nasais, realizou-se com tesoura de dissecção um descolamento do dorso e ápice nasal por meio de uma incisão intercartilaginosa por bisturi. A área descolada por cada narina foi unida na linha mediana para obter-se um descolamento completo.

Fez-se na seqüência uma incisão pré-cartilaginosa e dissecou-se o pericôndrio do ramo lateral da cartilagem alar maior até a incisão intercartilaginosa. Com o auxílio de pinças, foram expostos por eversão os ramos laterais das cartilagens alares maiores com seu "respectivo" domus (transição, em forma de joelho, entre os ramos lateral e medial).

Bilateralmente, demarcou-se com azul de metileno uma linha a partir da margem superior do domus paralela à margem inferior do ramo lateral da cartilagem alar maior até sua extremidade lateral, delimitando-se assim o excesso cranial de cartilagem alar a ser retirado (Figura 1). 


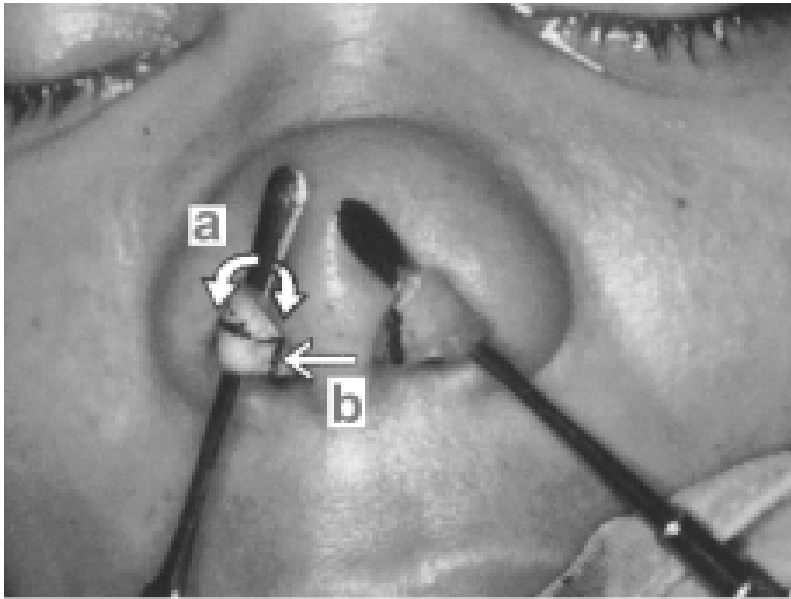

FIGURA 1 - Eversão dos ramos laterais das cartilagens alares maiores.

a - ressecção da cartilagem que excede a altura do domus (seta curva).

b - local onde é feita a sutura em U entre os domus (seta menor).

Fez-se uma sutura em U entre os domus das cartilagens alares maiores com fio monofilamentar inabsorvivel agulhado 5-0, deixando o fio reparado para o nó ser feito posteriormente..

A seguir, fez-se uma incisão de cerca $8,0 \mathrm{~cm}$ cranial ao sulco gengival superior para abordar via CaldwellLuck o terço médio da face, delineando um $\mathrm{Z}$ no frênulo do lábio superior.

Descolou-se o periósteo da maxila na extensão de $3,0 \mathrm{~cm}$ lateralmente à abertura piriforme até o ponto médio-lateral, em sentido caudo-cranial a partir da espinha nasal anterior (Figura 2).

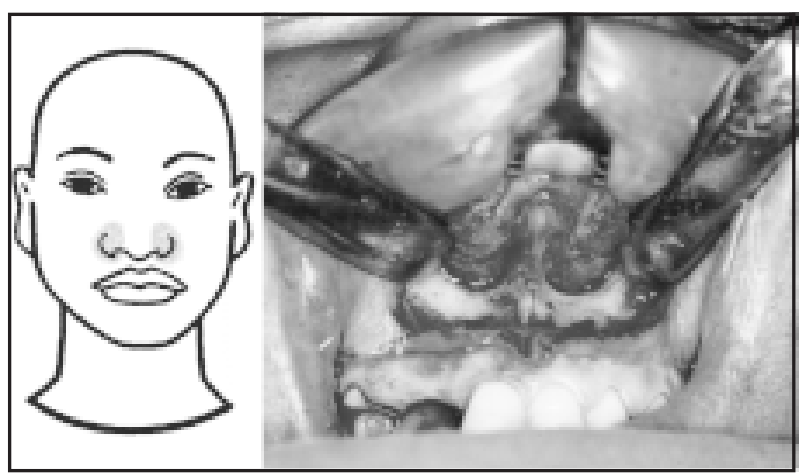

FIGURA 2 - Descolamento sub-periosteal. Pela via de CaldwellLuck faz-se um descolamento de $1,5 \mathrm{~cm}$ até o o ponto médiolateral da abertura piriforme.

Com a ponta de um bisturi de lâmina $\mathrm{n}^{\circ} 11 \mathrm{fez}$-se uma pequena incisão de $2 \mathrm{~mm}$ no ponto mais lateral e superior de cada vestíbulo nasal (Figura 3).

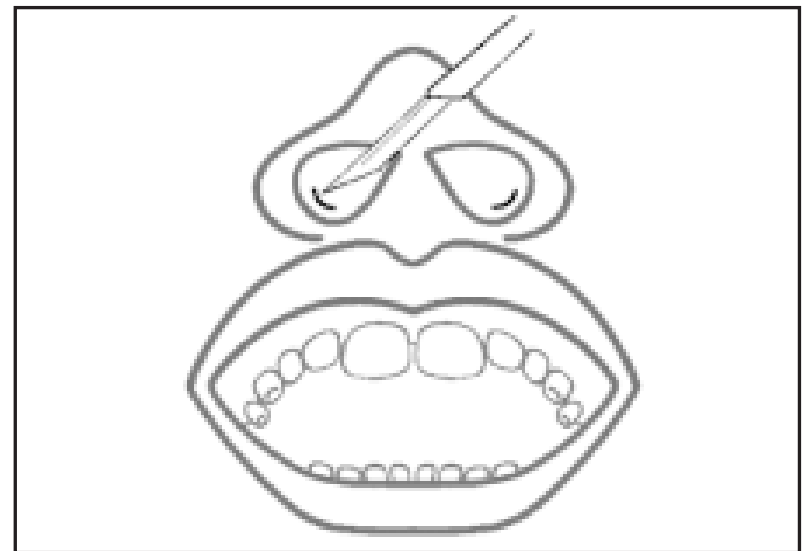

FIGURA 3 - Local da incisão. Com a ponta de um bisturí de lâmina 11 faz-se uma incisão de $2 \mathrm{~mm}$ nos no ponto superior dos vestíbulos nasais.

Pinçou-se com manobra bi-digital uma asa nasal para movimentá-la. Pela incisão intra-oral, com a outra mão identificou-se o tecido correspondente à implantação profunda daquela asa nasal, por onde se passou um fio monofilamentar inabsorvivel agulhado 3-0 até a agulha aflorar na pequena incisão no fundo do vestíbulo nasal. Em seguida fez-se o mesmo movimento em sentido reverso, isto é, introduziu-se a agulha na mesma incisão vestibular até aflorar dentro da boca (Figura 4).

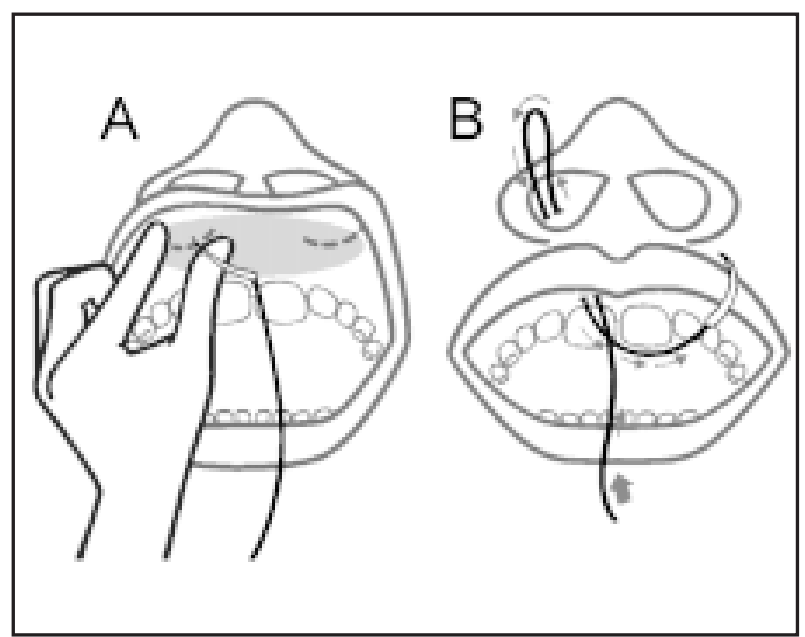

FIGURA 4 - Exteriorização do fio de sutura intra-oral nos vestíbulos nasais.

A - identificação da implantação profunda da asa nasal direita. B - sutura em U na implantação da asa nasal direita.

Tracionou-se a inserção profunda da asa em sentido medial para verificar se houve uma tração efetiva no intuito de tornar mais vertical o eixo longitudinal da narina (Figura 5). 


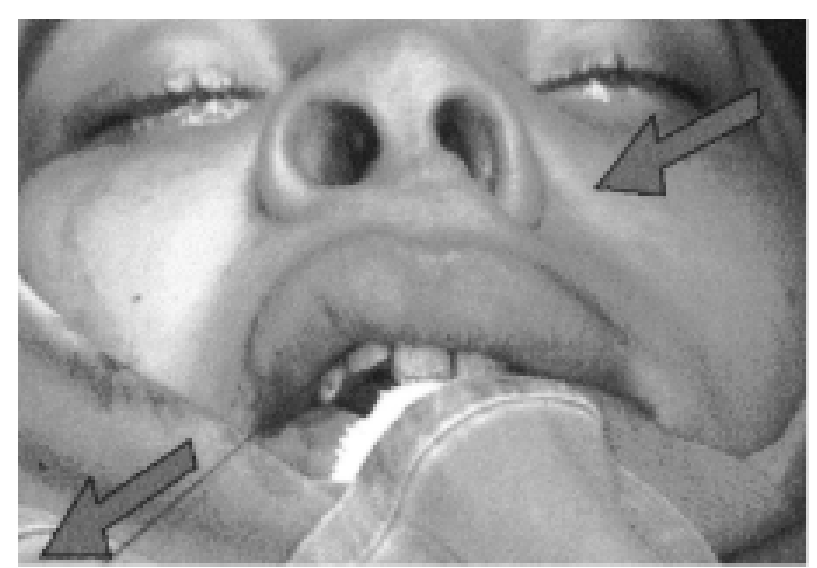

FIGURA 5 - Verificação da eficácia da sutura no sentido de verticalizar o eixo longitudinal da narina. Traciona-se com o próprio fio a implantação profunda da asa nasal (seta).

Somente então se continuou a sutura profunda em U na outra asa da mesma maneira, também se conferindo a verticalização do eixo longitudinal da outra narina, deixando ambas as alças do fio reparadas (Figura 6).

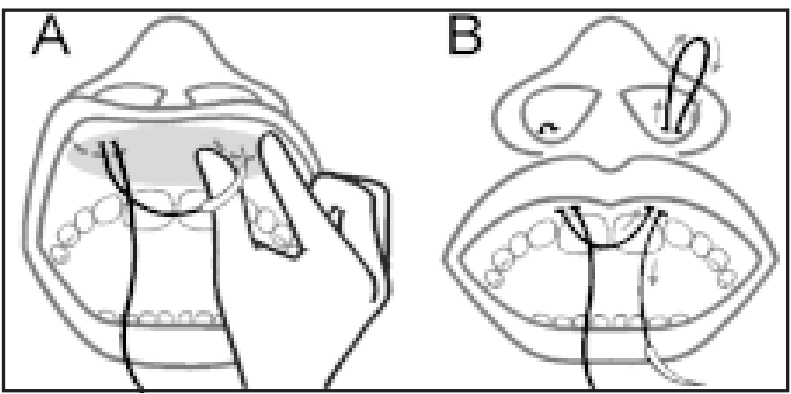

FIGURA 6 - Sutura em duplo-U, utilizando fio monofilamentar inabsorvível agulhado 3-0.

A - identificação da implantação profunda da asa nasal esquerda. B - ambas as extremidades do fio de sutura dentro da boca prontas para ser realizado o nó.

Nesse tempo operatório deu-se o nó definitivo na sutura entre os domus. A seguir, atou-se o nó do outro fio reparado por dentro da boca, apertando-o lenta e progressivamente até ser obtida a diminuição na largura da base nasal e a mudança simétrica na inclinação dos eixos das narinas (Figura 7).

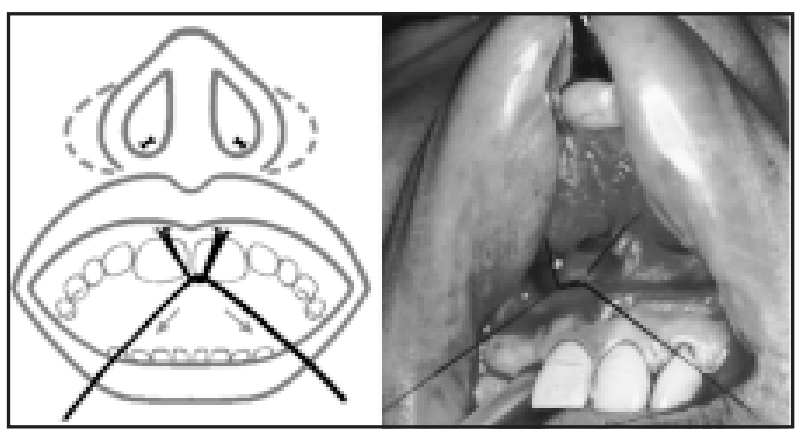

FIGURA 7 - Redução da largura da base nasal. Ao final da sutura em duplo-U, traciona-se e aperta-se o nó do fio de forma a diminuir a largura da base nasal e verticalizando simetricamente ambos os eixos longitudinais das narinas.
Formou-se um pilar muscular de cada lado do nó na incisão intra-oral correspondentes aos músculos abaixadores do septo nasal. Esses pilares foram aproximados e suturados com fio monofilamentar inabsorvivel 3-0 na linha mediana, de modo a cobrir e proteger o nó da sutura anterior e projetar ainda mais o ápice nasal (Figura 8).

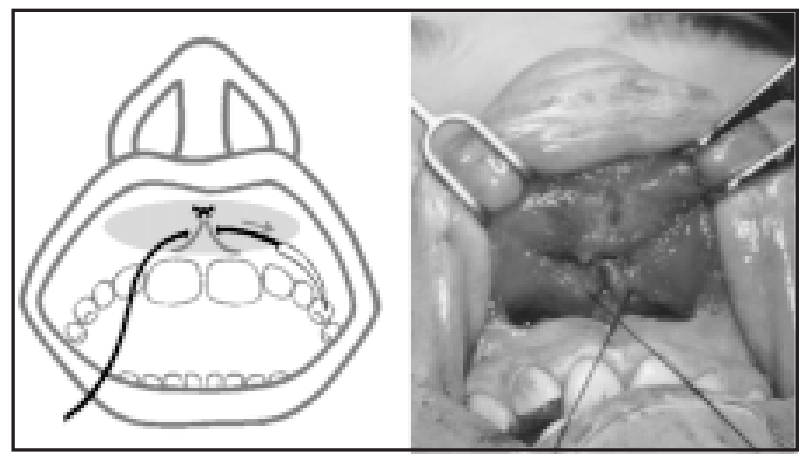

FIGURA 8 - Sutura simples dos pilares musculares correspondentes aos músculos abaixadores do septo nasal, encobrindo e protegendo o nó da sutura em duplo-U.

Suturou-se a incisão da mucosa oral com fio absorvível 4-0 agulhado, fazendo-se uma Z-plastia no frênulo do lábio superior para evitar possível retração posterior do mesmo. As incisões pré-cartilaginosas e intercartilaginosas foram suturadas também com o mesmo fio.

O curativo consistiu numa bandagem no dorso nasal com fita Microporeâ mantendo o ápice nasal ligeiramente suspenso e comprimindo a pele descolada. Finalmente, colocou-se um tampão nasal em cada narina por 24 horas.

Os procedimentos desta pesquisa prospectiva foram aprovados pelo Comitê de Ética em Pesquisa da UNIFESP / EPM.

\section{2 - Documentação fotográfica e fotogrametria computadorizada}

A avaliação dos resultados das operações foi realizada mediante a comparação de medidas obtidas com o auxilio de computador, a partir de fotografias em papel comuns pré e pós-operatórias.

As posições escolhidas para fotografar foram anterior, perfil direito e basilar ${ }^{(9)}$.

As fotografias em posição anterior e de perfil direito foram obtidas com o paciente em posição supina com o olhar dirigido à objetiva. A mesma foi fixada para uma distância focal de $70 \mathrm{~cm}$ do ápice nasal.

Para a obtenção da fotografia basilar foram demarcados com pequeno ponto de tinta sobre a pele os pontos antropométricos PRN (Pronasale, ou ponto mais anterior do ápice nasal) e $\mathrm{G}$ (Glabella, ou ponto ósseo mais 
proeminente entre os supercílios na linha mediana, facilmente perceptível pela palpação $)^{(2,10)}$. O ângulo de inclinação caudo-cranial da cabeça do paciente foi padronizado quando ambos os pontos ficassem alinhados no visor da câmera ${ }^{(11)}$. Para essa posição a objetiva foi fixada para uma distância focal de $45 \mathrm{~cm}$ do ápice nasal.

O equipamento fotográfico empregado foi uma máquina tipo monoreflex com objetiva de $50 \mathrm{~mm}$, com filme colorido ASA 100 de $135 \mathrm{~mm}$, revelado em papel fotográfico do tamanho padrão de $10 \times 15 \mathrm{~cm}$. Foi utilizado flash com fotômetro automático, e a câmera foi regulada com abertura de diafragma de 5,6 e com velocidade de obturador de 1/60.

Os pacientes foram fotografados antes da operação e com 3 meses de pós-operatório pelo mesmo operador, equipamento e nas mesmas posições.

A digitalização das fotografias foi realizada por scanner de mesa com 300 DPI em computador pessoal com processador Pentiumâ.

Para avaliar os resultados pós-operatórios foram escolhidos pontos antropométricos e foram calculados índices e ângulos relativos à base nasal (soft nose), ou seja, ao ápice nasal, asas e parte móvel do septo nasal.

Foi utilizado o programa gráfico Corel Drawâ 9.0 para mensurar esses parâmetros.

Nas fotografias em posição anterior foi calculado o Índice Nasal Frontal ${ }^{(5)}$ (INF) (modificado), que é a relação entre a medida da distância entre os pontos AL (Alar, ou ponto mais lateral da asa nasal) e a distância ao plano horizontal os pontos EN (Endocanthion, ou ponto correspondente à comissura palpebral medial) (Figura 9).

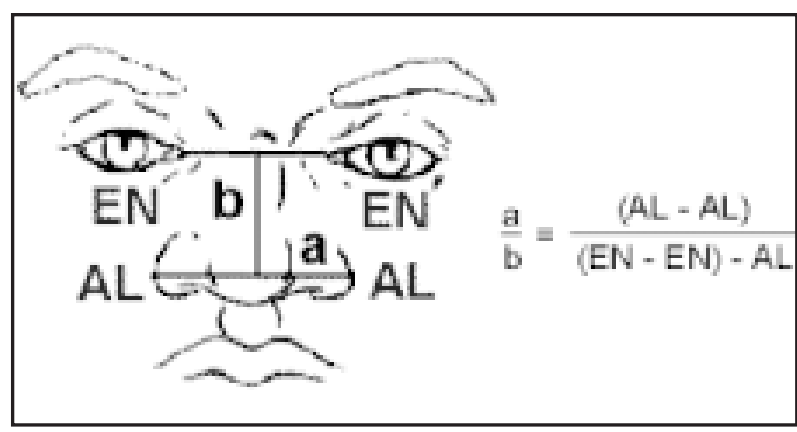

FIGURA 9 - Medida na posição anterior.

INF $=$ ÍNDICE NASAL FRONTAL

nariz negróide: INF $>0,85$.

- $\mathrm{EN}=$ Endocanthion $\bullet \mathrm{AL}=$ Alare

Nas imagens em perfil foram obtidos o Ângulo Nasolabial $^{(2,12)}$ (ANL) e o Índice de Projeção do Ápice $\mathrm{Nasal}^{(13)}$ (IPAN). O ANL é resultante da convergência ao ponto SN (Subnasale, ou ponto de transição entre a parte móvel do septo nasal e o lábio superior) de uma linha tangencial à parte móvel do septo nasal e outra linha tangencial ao ponto UV (Upper vermilion border, ou ponto médio do filtro labial, na transição cutâneomucosa do lábio superior). O IPAN é a relação da medida entre o ponto S (Sellion, ou ponto posterior do ângulo nasofrontal) ao ponto UV, e a medida entre o ponto PRN e o ponto C (Crumley, ou ponto de intersecção de uma linha perpendicular entre o ponto PRN e a linha $S$ UV) (Figura 10).

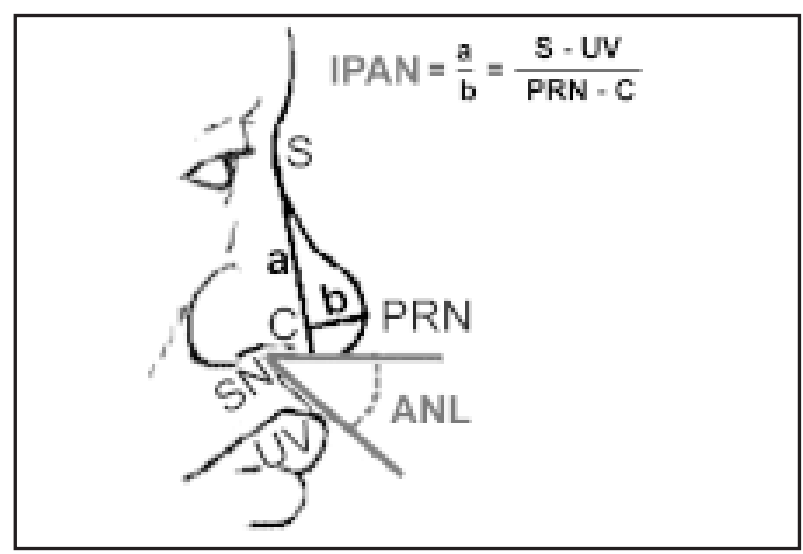

FIGURA 10 - Medidas na posição de perfil direito. ANL $=$ ÂNGULO NASOLABIAL IPAN = ÍNDICE DE PROJEÇÃO DO ÁPICE NASAL. $\cdot \mathrm{S}=$ Sellion $\bullet \mathrm{PRN}=$ Pronasale $\cdot \mathrm{C}=$ Crumley

$\cdot \mathrm{SN}=$ Subnasale $\cdot \mathrm{UV}=$ Upper vermilion border

Na visão basilar do nariz mediu-se o Ângulo Bi$\operatorname{Alar}^{(6,8)}$ (ABA), o Ângulo do Eixo da Narina ${ }^{(2)}$ (AEN) direita e esquerda, o Índice de Comprimento de $\mathrm{Asa}^{(2)}$ (ICA) (modificado) e o Índice Nasal Basal ${ }^{(8)}$ (INB) (Figura 11).

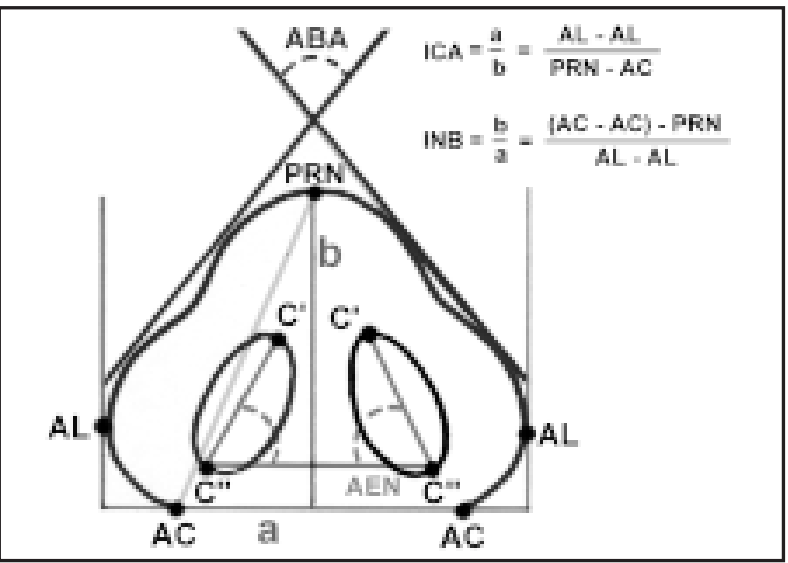

FIGURA 11 - Medidas na posição basilar. ABA $=$ ÂNGULO BIALAR AEN = ÂNGULO DO EIXO DA NARINA ICA = ÍNDICE DE COMPRIMENTO DE ASA $\mathrm{INB}=$ ÍNDICE NASAL BASAL.

$\cdot \mathrm{P}=$ Pronasale $\cdot \mathrm{SN}=$ Subnasale

- $\mathrm{AC}=$ Alar Curvature $\cdot \mathrm{AL}=$ Alare

- $C^{\prime}=$ ponto anterior da parte móvel do septo nasal

- $\mathrm{C}^{\prime}$ = ponto posterior da parte móvel do septo nasal 
$\mathrm{O} \mathrm{ABA}$ é formado entre duas linhas tangenciais às margens das asas nasais.

O AEN é formado entre o eixo longitudinal de cada narina, demarcado pelos pontos C' e C" (Columela, ou ponto mais anterior e posterior da parte móvel do septo nasal, respectivamente) e uma linha horizontal que une ambos os pontos C".

O ICA é a relação da medida entre ambos os pontos $\mathrm{AL}$ e a medida entre os pontos PRN e AC à direita.

$\mathrm{O}$ INB é a relação da medida entre o ponto PRN à linha que une ambos os pontos $\mathrm{AC}$, e a medida entre o ponto mais lateral da superfície da asa nasal de cada lado.
A diferença de assimetria entre as narinas no período pré e pós-operatório, foi avaliada pelo cálculo da diferença de graus em valor absoluto entre o AEN direita e o AEN esquerda em cada tempo. O índice criado nesta pesquisa para quantificar essas diferenças de assimetria foi representado pelo Índice de Assimetria entre os Eixos das Narinas (IAEN).

As medidas lineares, angulares e índices propostos foram obtidos com as ferramentas do software, a partir das fotografias pré e pós-operatórias digitalizadas e ampliadas, pela mesma pessoa (Figura 12).
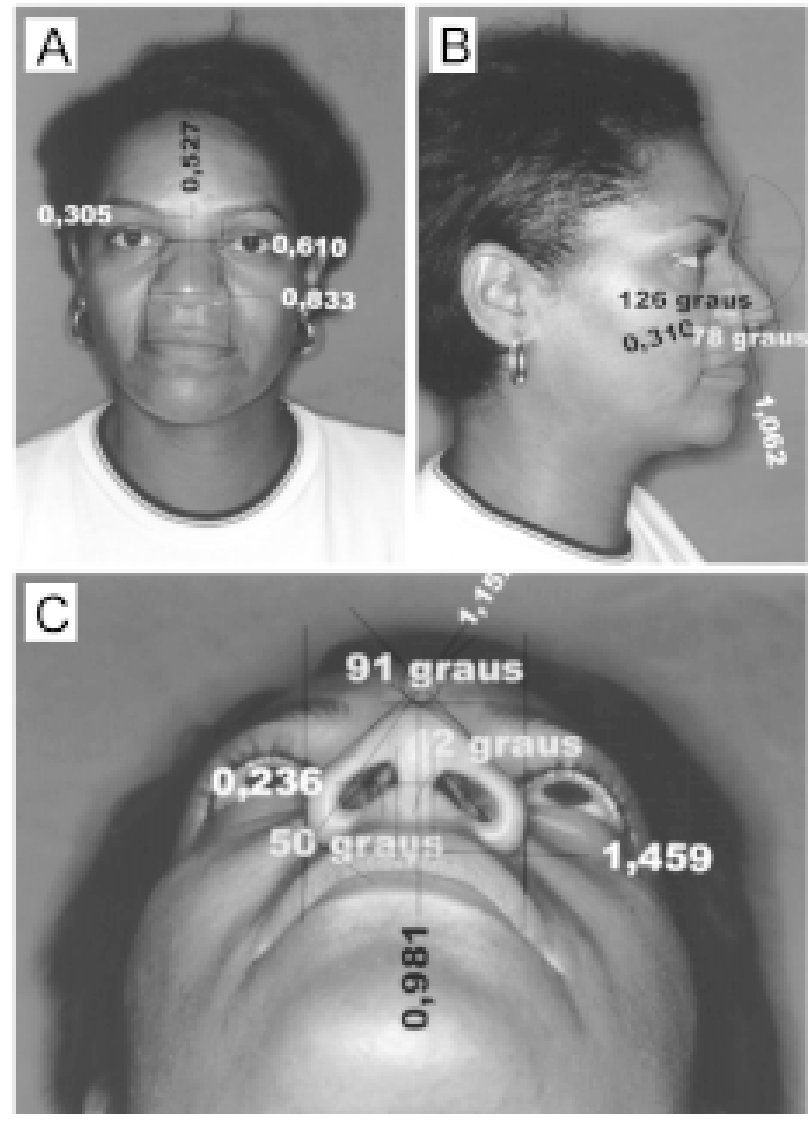

FIGURA 12 - Fotogrametria digitalizada computadorizada.

A - posição anterior

B - posição em perfil direito

C - posição basilar

\section{4 - Análise estatística}

Após a coleta de dados foi realizada uma análise estatística descritiva e uma análise inferencial.

A análise estatística constou do cálculo de medidas-resumo antes e após a operação.

A análise inferencial foi realizada para investigar a possibilidade de alteração nos índices avaliados em função da operação, tendo sido aplicado o teste t de Student pareado.

\section{RESULTADOS}

Os resultados obtidos neste trabalho indicam pouca variação nas medidas anteriores e posteriores à operação em relação ao estreitamento da base e projeção do ápice nasal pelos valores de INF, IPAN, ABA, AEN, ICA e INB, assim como na medida de IAEN.

Foi constatada apenas uma diferença estatisticamente significante $(\mathrm{p}=0,01)$ em relação ao aumento do Ângulo Nasolabial (ANL) (Tabelas 1 e 2). 
TABELA 1 - Medidas-resumo das variáveis registradas nos pacientes, antes e após a cirurgia.

\begin{tabular}{|c|c|c|c|c|c|}
\hline VARIÁVEL & Média & $\begin{array}{c}\text { Erro } \\
\text { padrão }\end{array}$ & $\begin{array}{l}\text { Desvio } \\
\text { padrão }\end{array}$ & Assimetria & Curtose \\
\hline Índice Nasal Frontal - Pré & 1,30 & 0,06 & 0,22 & $-0,40$ & 0,61 \\
\hline Índice Nasal Frontal - Pós & 1,33 & 0,07 & 0,23 & 0,08 & 0,10 \\
\hline Ângulo Naso-Labial - Pré & 87,91 & 2,54 & 8,42 & 0,64 & $-0,32$ \\
\hline Ângulo Naso-Labial - Pós & 102,82 & 3,61 & 11,98 & 0,07 & $-1,20$ \\
\hline Ind. De Proj. do Ápice Nasal - Pré & 4,05 & 0,14 & 0,47 & 0,90 & 1,62 \\
\hline Ind. De Proj. do Ápice Nasal - Pós & 3,93 & 0,14 & 0,45 & 1,32 & 3,21 \\
\hline Ângulo Bi-Alar - Pré & 91,09 & 5,24 & 17,38 & $-0,40$ & $-0,66$ \\
\hline Ângulo Bi-Alar - Pós & 91,09 & 4,96 & 16,46 & $-1,10$ & 2,87 \\
\hline Âng. Do Eixo da Narina dir. - Pré & 45,27 & 3,08 & 10,22 & 0,48 & 0,22 \\
\hline Âng. Do Eixo da Narina dir. - Pós & 43,18 & 2,33 & 7,74 & $-0,60$ & $-1,12$ \\
\hline Âng. Do Eixo da Narina esq. - Pré & 40,82 & 2,90 & 9,63 & 0,38 & 0,06 \\
\hline Âng. Do Eixo da Narina esq. - Pós & 39,73 & 2,37 & 7,86 & $-0,63$ & $-0,38$ \\
\hline Índice de Compr. de Asa - Pré & 1,28 & 0,04 & 0,14 & $-1,27$ & 1,86 \\
\hline Índice de Compr. de Asa - Pós & 1,28 & 0,04 & 0,12 & $-1,87$ & 5,22 \\
\hline Índice Nasal Basal - Pré & 0,63 & 0,04 & 0,14 & 1,31 & 2,20 \\
\hline Índice Nasal Basal - Pós & 0,63 & 0,02 & 0,07 & 0,59 & 1,75 \\
\hline Índice de Assimetria Narinas- Pré & 4,45 & 0,87 & 2,88 & $-0,31$ & $-1,73$ \\
\hline Índice de Assimetria Narinas- Pós & 3,82 & 0,90 & 2,99 & 0,95 & $-0,34$ \\
\hline
\end{tabular}

TABELA 2 - Resultados do teste de Student (análise inferencial).

\begin{tabular}{lcc}
\hline \multicolumn{1}{c}{ VARIÁVEL } & Estatística t & Nível descritivo \\
\hline Índice Nasal Frontal & $-0,869$ & 0,405 \\
Ângulo Naso-Labial & $-4,998$ & $\mathbf{0 , 0 0 1}$ \\
Índice de Projeção do Ápice Nasal & 1,467 & 0,173 \\
Ângulo Bi-Alar & $<0,001$ & 0,999 \\
Ângulo do Eixo da Narina direita & 1,462 & 0,174 \\
Ângulo do Eixo da Narina esquerda & 0,522 & 0,613 \\
Índice de Comprimento de Asa & 0,241 & 0,814 \\
Índice Nasal Basal- & 0,231 & 0,822 \\
Índice de Assimetria das Narinas & 0,629 & 0,543 \\
\hline
\end{tabular}

\section{DISCUSSÃO}

OFODILE, BOKHARI e ELLIS (1993) ${ }^{(12)}$ relevaram o fato do nariz negróide ser abordado inadequadamente como uma entidade padronizada, ou seja, apenas como se fosse uma variante pigmentada do nariz caucasóide com base larga. A dificuldade na correção deste tipo de nariz é traduzida pela diversidade de técnicas e táticas operatórias.

Apesar da operação do nariz negróide basear-se na tríade "redução das asas - estreitamento da base aumento do perfil", optou-se em escolher pacientes que não tinham indicação formal de aumentar o dorso, para assim obter-se uma avaliação sem interferência de procedimentos não realizados na base nasal, objeto do nosso estudo.

FARKAS, HRECZKO e DEUTSCH $(1983)^{(1)}$ concluíram que o cálculo de medidas antropométricas é mais preciso por fotogrametria do que por mensuração direta (antropometria direta). De fato, a fotogrametria computadorizada conforme proposta por HOCHMAN, CASTILHO e FERREIRA (2002) ${ }^{14}$ propiciou boa nitidez nos limites das estruturas que foram mensuradas, possibilitando maior precisão na obtenção das medidas.

A maioria das técnicas se preocupam em corrigir a base nasal e diâmetro das narinas ressecando tecido cutâneo, deixando intactos os tecidos profundos. 
SANTANA (1991) ${ }^{(6)}$ ao descrever a técnica de rinoplastia de nariz negróide sem ressecções externas pela via de Caldwell-Luck, relatou que obteve resultados satisfatórios, embora não tenha detalhado o período pós-operatório observado.

$\mathrm{Na}$ técnica operatória utilizada nesta pesquisa, baseada na técnica de SANTANA ${ }^{(6)}$, as fotografias do intra-operatório e a impressão visual da equipe no período pós-operatório mediato das pacientes foram de um bom resultado obtido no sentido de reduzir a base do nariz, embora isento de análise estatística nessa fase (Figura 13). Porém, num período pós-operatório relativamente precoce de 3 meses, constatou-se que houve uma recidiva estatisticamente significante no alargamento da base com horizontalização dos eixos longitudinais das narinas.

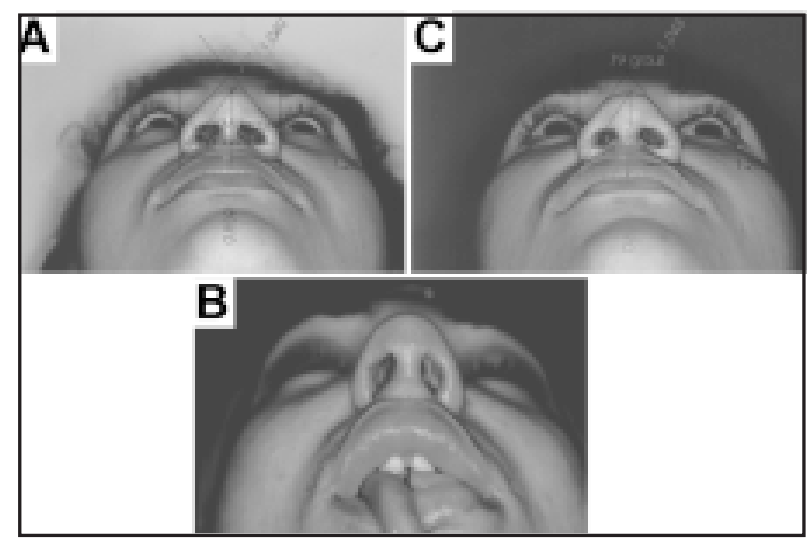

FIGURA 13 - Visão basilar do nariz.
A - pré-operatório
C - pós-operatório ( 3 meses)

B - intra-operatório (notar o bom resultado imediato)

DANIEL e FARKAS (1988) ${ }^{(10)}$ já haviam cogitado a existência desse "efeito mola" em técnicas de correção de nariz negróide com ressecção de pele, provavelmente devido à tração lateral contínua exercida pelos músculos da face. Portanto, esse efeito também estaria presente nesta técnica, apesar da desinserção de toda a musculatura da metade inferior da abertura piriforme e da presença do ponto em duplo-U sub-nasal. Esse ponto, além de estreitar a base nasal, teria como função que as fibras musculares se inserissem em novos sítios ao redor da abertura piriforme, tentando desfazer o "efeito mola". Outro reforço utilizado nesta técnica para romper dito efeito, constituído pelo descolamento da pele e das fibras musculares do dorso nasal, para que se inseriram em outros pontos, também não foi suficiente.

Corroboraria ainda para a formação do "efeito mola" o fato do diâmetro transverso da abertura piriforme ser maior nos indivíduos portadores de nariz negróide, o que poderia acarretar em inserções musculares com diferente configuração daquela do indivíduo caucasóide $^{(6)}$

Observou-se que a assimetria entre os ângulos de inclinação dos eixos longitudinais das narinas existente antes da operação mudava de magnitude após a operação.

Talvez o "efeito mola" não tivesse uma distribuição homogênea devido à mobilização dos tecidos internos na presença de suturas profundas. Essa mudança de assimetria pode não ocorrer nas operações com excisões e suturas externas, porém não há informações na literatura a respeito.

Por isso, houve necessidade de criar o Índice de Assimetria entre os Eixos das Narinas (IAEN) para avaliar essa alteração, o qual não apresentou variação estatisticamente significante.

Embora a amostragem de 11 pacientes seja relativamente pequena de forma que diferenças mais sutis não possam ser detectadas, houve alteração estatisticamente significante apenas nas medidas pré e pós-operatórias do Ângulo Nasolabial (ANL). Nas outras medidas relativas à base nasal não se registraram variações significantes (INF, IPAN, ABA, AEN, ICA, INB e IAEN).

Esse aumento do Ângulo Nasolabial foi obtido com a técnica empregada sem a necessidade de ressecção de cartilagem septal. Essa ocorrência veio de encontro com a afirmação de REES (1969) ${ }^{(15)}$, que já havia advertido que a margem inferior do processo posterior da cartilagem do septo nasal possui freqüentemente uma concavidade em narizes tipo negróide, o que dispensaria via de regra qualquer ressecção desta parte do septo.

Não fez parte do propósito deste trabalho discutir as indicações de operação de nariz negróide e não foram consideradas outras características como aspectos psicológicos relevantes dos pacientes. Porém, é interessante citar que houve uma satisfação da maioria das pacientes em relação ao resultado da operação, fato que foi inesperado e surpreendente para a equipe cirúrgica.

OFODILE e col. (1993) ${ }^{(12)}$ definiram genericamente a operação de nariz negróide, que não é um tipo de nariz específico de indivíduos da raça negróide, como modalidade operatória de "caucasoidização". O nariz com Ângulo Nasolabial maior é mais característico de pessoas caucasóides. Assim, o aumento significante obtido nesse ângulo, associado à intenção e expectativa das pacientes em "caucasoidizar" o nariz, talvez possam explicar essa satisfação, apesar que não se pretendeu com essa operação imitar um nariz caucasóide, e sim melhorar as características do nariz dentro do padrão de beleza e coerência racial da pessoa. FARKAS, 
KOLAR e MUNRO (1986) ${ }^{(2)}$ já haviam chamado a atenção que em mulheres consideradas atraentes, a relação entre o nariz e a face é mais estável do que entre as partes do nariz.

Outras táticas no sentido de aprimorar esta técnica por via intra-oral podem ser pesquisadas, no intuito de evitar as desvantagens e riscos das técnicas com cicatrizes externas em pessoas geralmente de cor negra. Uma ampliação do descolamento sub-periosteal e uma abrasão da superfície óssea para anular a "memória" das inserções das fibras musculares na mesma, assim como a associação de uma miotomia ou miectomia lateralmente às asas nasais para diminuir a tração dos músculos faciais, podem ser recursos para neutralizar o "efeito mola". Outra opção possível seria reforçar o arcabouço nasal com enxertos cartilaginosos no dorso e na porção móvel do septo nasal, para aumentar a resistência na base nasal à tração da musculatura facial.

O leque de estudos e sugestões permanece aberto no sentido de encontrar uma técnica mais definitiva para a correção do nariz negróide.

\section{CONCLUSÃO}

A operação para correção de nariz negróide por via intra-oral sem ressecções externas não apresentou variação estatisticamente significativa nos resultados após 3 meses nos índices relativos à largura da base nasal e à inclinação dos eixos longitudinais das narinas, não sendo portanto eficaz ao propósito a que se destina.

\section{REFERÊNCIAS}

1. Farkas LG, Hreczko TA, Deutsch CK. Objective assessment of standard nostril types-a morphometric study. Ann Plast Surg 1983;11(5):381-9.

2. Farkas LG, Kolar JC, Munro IR. Geography of the nose: a morphometric study. Aesthetic Plast Surg 1986;10:191-223.

3. Kamer FM, Parkes ML. The conservative management of the negro nose. Laryngoscope 1975;85(3):551-8.

4. Bernstein LB. Rhinoplasty for negroid nose. Otolaryngol Clin North Am 1975;8(3):783-95.

5. Matory WE, Falces E. Non-caucasian rhinoplasty: a 16-year experience. Plast Reconstr Surg 1986;77(2):239-51.

6. Santana PSM. Treatment of the negroid nose without nasal alar excision: a personal technique. Ann Plast Surg $1991 ; 27(5): 498-507$.

7. Ward CM. An analysis, from photographs, of the results of four approaches to elongating the columela after repair of bilateral cleft lip. Plast Reconstr Surg 1979;64(1):68-76.

8. Watanabe K. New ideas to improve the shape of the ala of the oriental nose. Aesthetic Plast Surg 1994;18:337-44.

9. Zarem HA. Standards of photography. Plast Reconstr Surg 1984;74(1):137-46.

10. Daniel RK, Farkas LG. Rhinoplasty: image and reality. Clin Plast Surg 1988;15(1):1-10.

11. Webber WB. Rhinoplasty: the importance of consistent documentation and significant long-term follow-up. Plast Reconstr Surg 1987;79(4):640-54.

12. Ofodile FA, Bokhari FJ, Ellis C. The black american nose. Ann Plast Surg 1993;31(3):209-19.

13. Crumley LC, Lanser M. Quantitative analyses of nasal tip projection. Laryngoscope 1988;98:202-8.

14. Hochman B, Castilho HT, Ferreira LM. Padronização fotográfica e morfométrica na fotogrametria computadorizada do nariz. Acta Cir Bras 2002; no prelo.

15. Rees TD. Nasal Plastic surgery on the negro. Plast Reconstr Surg 1969;43(1):13-8. 
Castilho HT, Hochman B, Ferreira LM. Negroid nose's rinoplasty through intra-oral approach without external excisions: evaluation of the efficiency of the technique. Acta Cir Bras [serial online] 2002 Sept-Oct;17(5). Available from URL: http://www.scielo.br/acb.

ABSTRACT - Objective: To evaluate effectiveness of the technique of reduction of the width of the nasal base of negroid nose, modifying the inclination of the axes of the nostrils for the mobilization of internal tissues, through intra-oral approach, avoiding external scars. Methods: Eleven adult female patients were operated with age varying between 19 to 45 years old, being distributed in 2 of the Caucasoid race and 9 of negroid race, being of this 5 brown color and 4 of black color. The picture method was standardized, and images in paper were digitized. Through software they were measured in the pre-operative pictures and with 3 months after the rhinoplasty. 8 relative indexes to the nasal base based on anthropometrics points. The obtained values were submitted to statistically descriptive analysis. Results: No significant statistically differences were found in seven of these features, relative reduction of the width of the nasal base and the variation in the axis of the nostrils inclinations. Just one significant alteration found, an increased in the nasal labial angle $(\mathrm{p}=0,001)$. Conclusion: The technique of rhinoplasty of negroid nose through intra-oral approach without external resection, just with mobilization of the internal tissues is not effective to reduce the nasal base.

KEY WORDS - Nose. Rinoplasty. Negroid race. Anthropometry. Photography. Photogrammetry.

Conflito de interesse: nenhum

Endereço para correspondência:

Prof. Dr. Helton Traber de Castilho

Disciplina de Cirurgia Plástica / Departamento de Cirurgia

Universidade Federal de São Paulo

Rua Napoleão de Barros, $715 / 4^{\circ}$ andar

04024-900 São Paulo - SP

Tel: (11) 5576-4118

traber@amhanet.com.br
Fonte de financiamento: nenhuma

Data do recebimento: 22/07/2002

Data da revisão: $12 / 08 / 2002$

Data da aprovação: 02/09/2002 